\title{
Cambodians' Support for the Rule of Law on the Eve of the Khmer Rouge Trials*
}

\author{
James L. Gibson \\ Sidney W. Souers Professor of Government \\ Department of Political Science \\ Professor of African and African American Studies \\ Director, Program on Citizenship and Democratic Values \\ Weidenbaum Center on the Economy, Government, and Public Policy \\ Washington University in St. Louis \\ Campus Box 1063 \\ St. Louis, MO 63130-4899 \\ United States \\ jgibson@wustl.edu
}

Fellow, Centre for Comparative and International Politics

Professor Extraordinary in Political Science

Stellenbosch University (South Africa)

\author{
Jeffrey Sonis \\ Assistant Professor of Social Medicine \\ Assistant Professor of Family Medicine \\ University of North Carolina at Chapel Hill \\ Department of Social Medicine \\ School of Medicine \\ CB No. 7240 \\ University of North Carolina at Chapel Hill \\ Chapel Hill, NC 27599-7240

\section{Sokhom Hean} \\ Director \\ Center for Advanced Study \\ Phnom Penh, Cambodia
}

Version 1.27

October 8, 2009

(C)

\footnotetext{
*This study was supported by a grant from the United States Institute of Peace, USIP-094-06S. The views expressed in this article are those of the authors and do not necessarily reflect the opinions of the United States Institute of Peace.
} 


\begin{abstract}
Cambodia is in the midst of trying some of the leaders of the Khmer Rouge for their actions during the time of the Killing Fields. Beyond the effects on individual victims and perpetrators, many will ask whether this process of historical accountability will have a broader impact on Cambodian society and political culture.

One possible consequence of the trials is that the attitudes of ordinary Cambodians toward the rule of law will be affected. One hypothesis is that the trials will restore faith in the rule of law, a faith undermined by the failure of the state to take action against the miscreants for thirty years. Other hypotheses are also tenable.

The purpose of this paper is to examine the attitudes of Cambodians toward the rule of law. Based on a nationally representative survey conducted in 2007 - well before the trials began - our evidence is that Cambodians hold an extremely strong preference for strict adherence to legal universalism. Because support for the rule of law is so strong, the trials are highly unlikely to make it stronger. From the pointof-view of transitional justice processes, we argue that (1) it is crucial to know the state of society prior to the implementation of justice processes so that change can be measured; (2) cultural values such as support for the rule of law are as likely to be causes of transitional justice processes as they are results; and (3) because much too little is known about the societal consequences of transitional justice processes, much more rigorous, quantitative analysis must be conducted.
\end{abstract}


The trials of the former leaders of the Khmer Rouge (KR) began earlier this year. In July 2007, Duch (Kaing Guek Eav) was charged with crimes against humanity, grave breaches of the Geneva conventions of 1949, torture and murder for his role as chief at the S21 prison in the capital, Phnom Penh (Extraordinary Chambers, 2009). Four other Khmer Rouge leaders are in custody, awaiting trial, and others — perhaps even former king Norodom Shihanouk — may be required to appear before the Extraordinary Chamber in the Courts of Cambodia (ECCC). The future is still quite uncertain, but some measure of justice may yet come to the land of the killing fields.

The trials have several purposes. Obviously, holding the leaders of the former regime accountable for human rights violations during their reign of terror is a primary objective of the process. But the trials also seek a broader goal: what might be called reconciliation. Although the term has many - and many contested - meanings, reconciliation generally involves societal transformation, with friend and foe seeking a means of living together in peaceful tolerance and coexistence. As with virtually all transitional justice processes, the Cambodian efforts to address its past seek several objectives simultaneously.

For instance, one important aspect of reconciliation, according to Gibson’s (2004) analysis of the South African truth and reconciliation process, is support for the rule of law: Citizens must value the rule of law and be willing to support limits on the actions government can undertake. The rule of law is important since it can stand as an impediment to tyrannical rule. To the degree that a political culture holds law in high esteem, the arbitrary rule often preferred by tyrants is discouraged. Consequently, it is not surprising that building a "rule of law culture” was one of the specific mandates assigned to South Africa's Truth and Reconciliation Commission (TRC). One aspiration of the Khmer Rouge trials is to hold the leaders responsible for their actions (albeit belatedly) and thereby to build respect for the rule of law within Cambodian society.

Reconciliation is a process of change. Unfortunately, however, change is rarely analyzed in studies of reconciliation. Gibson's (2004) important study of South Africa, for instance, is based on a single cross-sectional survey, so, even though he uses statistical and logical techniques to make inferences 
about change, such inferences inspire only limited confidence that truth actually caused a change in reconciliation. Although dynamic inferences can be (and routinely are) made from static data, the most useful research design for studying the effects of such processes as the Khmer Rouge trials is a longitudinal one.

This paper does not report a longitudinal analysis, however. Instead, the purpose of this paper is to investigate the "baseline" condition of Cambodian political culture prior to the initiation of the KR trials. In particular, we assess the degree to which Cambodians regarded the rule of law highly prior to the trials. The basic assumption of many is that human rights abuses from the past undermined support for the rule of law, and that some process must be implemented in order to rectify that deficit. Based on a nationally representative survey conducted in early 2007, we investigate that hypothesis. Our specific purposes here are to assess several empirical questions. (1) How supportive are Cambodians of the rule of law? (2) How do Cambodians compare with citizens of other polities? (3) Are young Cambodians, who did not directly experience the terror of the KR, different from and more supportive of the rule of law than older Cambodians? (4) More specifically, is there a connection between suffering abuses under the prior regime and one's attitudes toward law today? By answering these questions, we will establish a baseline of support for the rule law, against which changes over the course of the trials can be assessed. Establishing the initial level of support for the rule of law - as well as how such support is distributed throughout Cambodian society - is crucial if the effects of this transitional process are to be accurately estimated and assessed.

The most important findings of this paper are that support for the rule of law is widespread in Cambodian society even well before the trials of the KR leaders commenced. Indeed, in comparative perspective, the Cambodians revere the rule of law as much as any polity within which surveys of mass opinion have been conducted. Our most general conclusions are that the horrific Cambodian past has caused citizens to value the rule of law, that public support for the rule of law may well have been a cause of the ECCC rather than a consequence of it, and that any efforts to understand the impact of the ECCC 
on Cambodian political culture must consider the nature of that culture prior to the creation and implementation of the tribunal.

\section{The Rule of Law and Democratic Theory}

Democratic theorists have long placed a great deal of emphasis on the rule of law as a crucial contributor to effective democracy. In its minimalist manifestation, the rule of law is little more than proper procedure. It asserts that, in a democracy, rulers are bound to rule via established procedures and legal constraints. The rule of law constrains discretion; what one may prefer to do at the moment may not be possible owing to existing law. From this perspective, the rule of law implies little substantive content. ${ }^{1}$ Instead, it is rule by procedure. As Lipset has noted:

Where power is arbitrary, personal and unpredictable, the citizenry will not know how to behave, will fear that any action may produce an unforeseen risk. Essentially, the rule of law means at least two things: one, that people will be treated equally by the institutions administering the law, the courts, the police, and the civil service; second, that they can predict with reasonable certainty the consequences of their actions, at least as far as the state is concerned (Lipset 1994, 15).

An important function of the rule of law is to impede tyranny. The logic is simple and compelling. Both masses and elites are often confronted with circumstances in which their interests are at odds with the requirement of democratic politics. Masses may wish to stifle political expression by

\footnotetext{
${ }^{1}$ According to the Secretary-General of the United Nations, the rule of law "refers to a principle of governance in which all persons, institutions and entities, public and private, including the State itself, are accountable to laws that are publicly promulgated, equally enforced and independently adjudicated, and which are consistent with international human rights norms and standards. It requires, as well, measures to ensure adherence to the principles of supremacy of law, equality before the law, accountability to the law, fairness in the application of the law, separation of powers, participation in decision-making, legal certainty, avoidance of arbitrariness and procedural and legal transparency" (Report of the Secretary-General 2004, 4, emphasis added). Thus, the Secretary-General disagrees with our understanding of the rule of law by imposing substantive requirements. Because it is so much easier to get agreement on procedures from all sides in politics, in contrast to attaining consensus on substantive policy outcomes, our definition is a minimalist (and pragmatic) one.
} 
unpopular minorities ${ }^{2}$; elites often seek ways to undermine the effectiveness of their political challengers.

The rule of law protects against arbitrary intrusions on individual liberty, be they from above or below.

Of course, pernicious schemes can be implemented through impeccable democratic procedures — South Africa’s apartheid was a legal edifice properly enacted by the country’s parliament — but to do so typically requires open debate and the agreement of the majority. In addition, legal procedure slows down disputes, allowing cooler heads to prevail. ${ }^{3}$ The rule of law requires that schemes of repression be openly implemented rather than simply pronounced by a ruler or a mob, thereby making repression more difficult to implement.

Within this context, the rule of law constrains both rulers and the ruled. The rulers must act according to legal procedure, which means they must rule through legislatures and courts. The ruled are obliged to follow these laws, to acquiesce to them. When the self interests of rulers and ruled conflict with the law, law must prevail, at least until it is changed via legitimate democratic procedure.

Thus, the essential ingredient of this construct is universalism - law ought to be universally heeded, that is, obeyed and complied with. To the extent that law generates an undesirable outcome, law ought to be changed through established procedures, rather than manipulated or ignored. Willingness to abide by the law is pivotal to the concept.

The antithesis of universalism is particularism, based typically on either expedience or on the substitution of some sort of moral judgment for legality. Some may feel that law should be set aside (or bent) in favor of solving problems quickly or efficiently, while others may be unwilling to accept legal

${ }^{2}$ It should not be assumed that all violations of the rule of law necessarily go against the perceived self-interest of the majority. For instance, Solomon (1992) points to instances in the former Soviet Union in which ordinary citizens demanded that the authorities dispense with the rule of law in dealing with suspects in notorious criminal cases. There were many instances in which South African "people's justice" had little to do with the rule of law (and perhaps not that much to do with justice either). It is easy to imagine that runaway crime is an instance in which the majority may be willing to sacrifice the rule of law for more expedient remedies.

${ }^{3}$ No better example of this can be found than in the controversy in Skokie, Illinois, on whether to allow a public demonstration by a small group of neo-Nazis. Gibson and Bingham (1985) have argued that by moving the dispute into the courts, delay was created, allowing passions to cool a bit, making a democratic outcome to the controversy more likely. Some refer to this as giving political conflicts a “sober second thought” (see Stouffer 1955; Gibson 1998). 
outcomes that, by some standards, are "unjust." ${ }^{4}$ To the extent that people are willing to follow the law only if it satisfies some external criterion, the rule of law is compromised. Respect for the rule of law thus means that following the law (universalism) is accorded more weight than other values that might trump legality, such as expediency or even fairness.

We must acknowledge, however, that freedom is sometimes lost under the guise of law; and not all authoritarian governments necessarily reject the rule of law. As Krygier reminds us: "There was, after all, a Nazi jurisprudence, and it was a horrible sight” (1990, 641). Much of the early Nazi attack on German Jews was accomplished under the authority of law. And of course, no government would repudiate the rule of law openly, since the rule of law is a powerful and seemingly universal means of legitimizing authority. Rule of law may be essential to democratic governance, but law can, under some circumstances, serve dictators as well as democrats. The correlation between strict adherence to legal universalism and democracy is certainly less than perfect.

\section{A Cultural Definition of the Rule of Law}

In an effective democracy, the rule of law must of course be manifest in the political institutions of the country — which is to say little more than that clearly defined, predictable procedures for both law making and law implementation must exist.

But rule of law is more than a set of institutions, more than a constitution and a statute book. Indeed, perhaps the most important manifestation of the rule of law is in its representation in a nation's culture - the set of beliefs, expectations, values, and attitudes held by the populace of a country. When we speak of corruption, for instance, as antithetical to the rule of law, we often are referring to a set of norms and expectations about whether corrupt behavior is acceptable within a polity. This refers to "ways of doing business,” which are in part institutionally determined, but which are in larger part culturally

${ }^{4}$ For earlier research using a similar conceptualization of universalism and particularism see Levin 1972, 1977; Wilson 1976; Gibson and Caldeira 1996; Gibson and Gouws 1997; and Gibson 2003, 2004, and 2007. 
legitimized. ${ }^{5}$ Acknowledging that institutions are important, Krygier (1990, 646, emphasis in original) points to "something far vaguer but fundamentally more important: a widespread assumption within society that law matters and should matter." Thus, we can speak of a rule of law both in terms of formal institutions and a rule of law culture. Without a culture that rejects the sublimation of law to other more pressing objectives, a Rechtsstaat cannot effectively function. ${ }^{6}$ Understanding how a political or legal system operates always requires far more than understanding the structure and function of institutions, but when it comes to understanding the meaning of the rule of law in a country, culture is paramount.

Analyses of cultural norms and values have a long and distinguished legacy within the social sciences (e.g., Almond and Verba 1963). But this approach has also achieved great currency lately among economists and legal analysts, as in their concern with social norms. Etzioni writes of the importance of these norms: “. . . it is widely held that strong social norms reduce the burden on law enforcement; that laws supported by social norms are likely to be significantly more enforceable; and that laws that are formulated in ways that are congruent with social norms are much more likely to be enacted than laws that offend such norms” $(2000,159)$. In essence, Etzioni and others are asserting that if we are to understand how law and politics actually operate within a polity, we need to look beyond institutions to examine the cultural norms and values that undergird the institutions and that shape the behavior of individual citizens.

\footnotetext{
${ }^{5}$ As Hoffman $(1998,148)$ asserts in the case of the Former Soviet Union: "The transformation of democratic forms into democratic norms . . . is crucial for democracy to take root throughout Russia." Diamond $(1999,65)$ concurs, noting that the consolidation of democratic reform is only possible when "political competitors ... come to regard democracy (and the laws, procedures, and institutions it specifies) as 'the only game in town,' the only viable framework for governing the society and advancing their own interests. At the mass level, there must be a broad normative and behavioral consensus - one that cuts across class, ethnic, nationality, and other cleavages - on the legitimacy of the constitutional system, however poor or unsatisfying its performance may be at any point in time."

${ }^{6}$ Many have argued that a rule of law state (a Rechtsstaat) is a necessary condition for democratic governance (e.g., Rose, Mishler, and Haerpfer 1998, 32-33). By this they mean that the state should be bound by law and cannot act arbitrarily or capriciously. Respect for the rule of law thus means that following the law (universalism) is accorded more priority than other values that might trump legality, such as expediency or even fairness.
} 


\section{The Rule of Law and Reconciliation}

Gibson's (2004) earlier research on reconciliation in South Africa explicitly postulates that one of the four pillars of reconciliation is mass support for the rule of law. According to this theory of reconciliation, for South Africa's nascent democracy to prosper, the political culture must be one in which the universalistic application of the rule of law - and the rejection of the arbitrary exercise of governmental authority and

power - is deeply valued and respected. The legislation establishing the TRC agreed with this theory, and called for the development of a culture respectful of human rights in South Africa. Perhaps the "first principle” of such a culture is respect for the rule of law. In particular, a human rights culture cannot be established without a commitment to the universal application of law, and especially the unwillingness to set law aside to accomplish other objectives. Thus, a reconciled society is one in which ordinary people support the rule of law, both as a constraint on their own actions and on the actions of the government.

To what extent is support for the rule of law pervasive within the Cambodian political culture? Our 2007 survey of a representative sample of Cambodians addresses this question.

\section{Research Design}

This research is based on a national probability sample of 1,017 adult Cambodians aged 18 years and older that was assembled using a multi-stage stratified cluster design. A face-to-face interview was conducted in 2006/2007 by trained interviewers employed by the Center for Advanced Study, a not-forprofit survey research organization, based in Phnom Penh, Cambodia.

The total sample was designed to be representative of the non-institutionalized population, 18 years old and older, of the Kingdom of Cambodia. However, we wanted to focus attention on adults who were at least three years of age at the start of the Khmer Rouge era, in 1975, 32 years prior to the start of the survey. Accordingly, we deliberately over-sampled adults over the age of 35 . 
Based on a standard formula from the American Association for Public Opinion Research (AAPOR), the cooperation rate, i.e., the percentage of persons who participated among those who were eligible, available and physically able to participate, was 94.2\%. The AAPOR response rate, i.e., the percentage of persons who participated among those who were eligible (both available and unavailable) and those of unknown eligibility, based on the assumption that all of the households of unknown eligibility were actually eligible (i.e., the assumption that would result in the lowest calculated response rate), was 59.5\%. If we assume, still conservatively, that eligibility among households of unknown eligibility was equal to the eligibility of all households of known eligibility (or $87.6 \%$ in this study), the response rate is $61.7 \%$. The difference between the cooperation rate and the response rate was due to a relatively large number of households $(\mathrm{N}=457)$ that were selected but which were vacant during the time of the survey. Sample demographic characteristics were similar to those of the Cambodian population. (See Sonis et al. (2009) for details.)

The questionnaire was translated into Khmer and back-translated into English using standard methodology. The instrument was extensively pilot-tested using the "talk aloud” method in a three-day group interview with a convenience sample of 15 residents of Phnom Penh and then further pilot-tested and revised with 60 respondents from rural areas near Phnom Penh.

The Center hired and trained 18 Cambodian research assistants from the Phnom Penh area who traveled in two separate research teams, from December 25, 2006 to January 23, 2007, throughout the country to conduct the survey. Because of logistical difficulties in getting to 4 villages in January 2007, interviews ( $\mathrm{N}=20)$ were conducted by one of the research teams in those villages between August 26, 2007, and August 28, 2007.

All analyses accounted for the sampling weights and the design effect introduced by the complex sampling scheme.

The research protocol was approved by the University of North Carolina Behavioral institutional review board. Since there is no equivalent structure in Cambodia, the protocol was also reviewed by a 
small group of local social scientists who had experience working with trauma survivors.

\section{Measuring Cambodian Support for the Rule of Law}

How supportive are Cambodians of the rule of law? In order to answer this question, empirical indicators of attitudes toward the rule of law must be developed and implemented in a representative survey of the Cambodian mass public.

Few people are likely to reject the rule of law in principle. Survey questions that ask people whether they agree that rulers ought not to act arbitrarily or capriciously or that citizens should be free to ignore the law as they please are unlikely to be of much use in tapping popular commitments to the rule of law. Instead, the difficult test of support for the rule of law involves the juxtaposition of law and some other valued principle. Questions are most useful when they force people to weigh the relative value of conflicting principles ${ }^{7}$; only when supporting the rule of law involves some cost can we begin to gauge how valuable the rule of law is to people.

Consequently, our survey asked people to agree or disagree (on a five-point Likert scale, ranging from agree strongly to disagree strongly) with statements pitting the rule of law against another value. In one measure, the other value was expediency. ${ }^{8}$ The statement is:

Sometimes it might be better to ignore the law and solve problems immediately rather than wait for a legal solution.

Some of those who oppose the rule of law also do so on grounds of pragmatism, arguing that the rule of law can be unnecessarily rigid and confining. Law must be flexible if it is to be effective. We therefore asked the respondents their opinions of the following statement.

${ }^{7}$ For a similar analysis of the relative value Americans ascribe to security and liberty see Davis and Silver 2004.

${ }^{8}$ Tamanaha (2004) provides a useful analysis of the concept of rule of law. He identifies three major themes in how the rule of law has been understood: government limited by law, formal legality, and rule of law, not man. Although these do not map directly on to the statements we use to measure rule of law attitudes, our empirical approach nonetheless fits well with his conceptualization. 
In times of emergency, the government ought to be able to suspend the law in order to solve pressing social problems.

Universalism in the application of the rule of law was measured with two statements:

It's alright to get around the law as long as you don't actually break it.

Government officials who are guilty of crimes deserve the same punishment as anyone else.

Another statement paired the rule of law with personal convictions:

An individual is obligated to obey the law for the good of society as a whole, even if he/she finds it personally unjustifiable.

Figure 1 reports responses of the respondents to these five propositions.

\section{[PLACE FIGURE 1 ABOUT HERE]}

Considerable variability exists in the replies of the respondents to these statements. ${ }^{9}$ At one extreme, nearly all Cambodians agree that government officials who commit wrongdoings should be subject to the same punishment as everyone else, and that individuals are obliged to obey laws even if they object to them. At the other extreme (which is not nearly so extreme), slightly less than a majority assert that it is unacceptable for a government to suspend laws in order to solve pressing social problems. In general, however, support for the rule of law seems fairly widespread in Cambodia, as evidenced by the fact that, across the set of five statements, the average number of responses favoring the rule of law is 3.8. These data seem to indicate quite substantial commitments to law even when paired against another value.

These data seem on their face to be incompatible with Cambodian institutions, which, to put it

${ }^{9}$ To reiterate, rule of law is a multi-dimensional concept, and there are other dimensions of the concept that are not explicitly considered here. We explored some of these in our earlier research, but those results revealed such widespread support for some aspects of the rule of law that we felt it wasteful to devote questions to what are essentially universally held views. Especially when propositions are phrased in the abstract, very few people believe that judges ought to be subservient to politicians, that governments ought to have the power to ignore law at will, and that law ought to be applied in an idiosyncratic, particularistic fashion, etc. On the contrary, the key idea about which people seem to divide is the degree to which law ought to be followed even when it produces seemingly undesirable results. 
mildly, are not generally admired for their strong attachment to the rule of law. ${ }^{10}$ Our view is that the answers to our rule-of-law questions most likely reflect the aspirations of the Cambodian people, not necessarily the realities of how Cambodian society operates. Indeed, as Duch and Gibson (1992) contend, people deprived of a political right or institution may well come to value that right or institution more highly than people who have grown accustomed to its protections. Most Cambodians seems to view the rule of law as a positive and desirable political value, irrespective of the realities of corruption and lawlessness in Cambodian society.

The five-item set of indicators has relatively low reliability $(\alpha=.58)$, which reflects a small average inter-item correlation (.17). ${ }^{11}$ This is largely a function of degenerate variance among the first two items in Figure 1 (i.e., nearly everyone agrees with the statements). When these variables are omitted from the set, alpha climbs to .74 (with an average inter-item correlation of .50). Factor analysis confirms that the three-item set is unidimensional. Thus, on the basis of reasonably strong evidence of its face validity and reliability, we use the three-item index as our measure of support for the rule of law. ${ }^{12}$

\section{Cross-National Comparisons}

Support of the Cambodians for the rule of law seems to be reasonably widespread. But in order to gain clearer perspective on the case of Cambodia, it is useful to compare these data to comparable surveys in other countries. Two of the statements used in Cambodia have also been included in surveys we have conducted in other parts of the world (see Gibson 2007). Figures 2 and 3 report the comparative data from

\footnotetext{
${ }^{10}$ For example, Cambodia ranks $166^{\text {th }}$ out of 180 countries evaluated on Transparency International's Corruption Perception Index, a ranking based on perceived levels of corruption as determined by expert assessments and opinion surveys (Transparency International, 2008).

${ }^{11}$ In turn, the low average inter-item correlation coefficient reflects a couple of negative correlations among the items, most of which are entirely trivial. One correlation, however, is not trivial: that between the first item in Figure 1 (government officers deserve the same punishment) and the last item (okay for government to suspend law). This correlation no doubt reflects the extreme lack of variance in the first item (as discussed further in the text).

${ }^{12}$ Since two of the original items are in essence constants, it is not surprising that the correlation between the three-item and five-item indices is .95.
} 
the various surveys in which these measures have been used. Many of these are established democracies in which one might assume support for the rule of law is deeply entrenched. ${ }^{13}$

\section{[PLACE FIGURES 2 AND 3 ABOUT HERE]}

For a variety of methodological reasons, care must always be taken in comparing cross-national survey results. Nonetheless, the conclusion to be drawn from these figures is that Cambodians are unusually strongly committed to the rule of law. Indeed, these data suggest that, on the eve of the KR trials, support for the rule of law among ordinary Cambodians was uncommonly widespread.

The comparison between Cambodia and France is noteworthy. On the statement reported in Figure 2, $95 \%$ of the Cambodians support the rule of law position, whereas only $67 \%$ of the French respondents do so. From Figure 3 we see that $74 \%$ of the Cambodians but only $48 \%$ of the French favor the rule of law. Thus, these data strongly support the conclusion that Cambodians yearn for the rule of law even more than citizens of some societies in which the rule of law seems firmly established. ${ }^{14}$

\section{Accounting for Variability in Support for the Rule of Law}

Next we consider whether support for the rule of law among ordinary Cambodians is related to two important variables: (1) age/generation, and (2) experiences of victimization under the KR regime. The first two of these variables were selected so as to try to estimate the contemporary residue of the KR atrocities. Since the young could not have directly experienced the KR regime, we hypothesize that older Cambodians express weakened support for the rule of law. As a more direct test of that hypothesis, we also examine whether being victimized under the KR regime is associated with lesser support for the rule of law.

\footnotetext{
${ }^{13}$ Note that in some countries, data from more than a single survey are included.

${ }^{14}$ It is worth reiterating that we do not argue that the beliefs of the mass public are the only attribute of importance when it comes to using law to protect against tyranny. The French have institutions, deeply legitimate ones, which could well be mobilized against tyrannical elites and masses. It is also conceivable that French elites are more committed to the rule of law than are ordinary French citizens. To repeat, the preferences of the mass public are only one element in a complex multivariate equation when it comes to preventing the rupture of the rule of law.
} 
Figure 4 reports the average response to the three rule-of-law statements for Cambodians of various age groups. As the data make clear, no relationship whatsoever exists between age and support for the rule of law. Older generations are not less likely to support the rule of law; the relationship is neither statistically nor substantively significant. Of course, age is only a rough surrogate for experiences under the Khmer Rouge regime, but from these data alone, it appears that those who survived KR rule are not less supportive of the rule of law than those who never lived under the hated regime.

\section{[PLACE FIGURE 4 ABOUT HERE]}

Have victimization experiences under the KR regime undermined support for the rule of law? Since this variable is quite theoretically interesting because it represents experiences directly at odds with the rule of law, we begin with an explication of the construction of the measure.

All respondents older than 35 years old were asked about whether they had experienced any of 10 different types of trauma under the KR regime. Figure 5 reports the results. To reiterate, these figures do not represent all Cambodian adults but are instead confined to those who lived under the KR regime.

\section{[PLACE FIGURE 5 ABOUT HERE]}

The data reveal wide variability in the types of trauma experienced, ranging from a large majority of respondents claiming to have been forcibly separated from their families to a tiny number who said they were raped or sexually assaulted. A majority of these respondents asserted that they had been separated from their families, were involved in combat, and that they were close to death under the rule of the Khmer Rouge. Thus, trauma from that era was extremely widespread. Indeed, the average number of traumatic events experienced by these respondents is 3.1.

The conventional hypothesis is that experiences with victimization during the KR era reduced support for the rule of law. This is the oft-heard impunity argument: When citizens see governmental wrongdoing on a massive scale going unpunished they become cynical about the rule of law. And because citizen regard for the rule of law is thought to be weak and uncommon, a reconciliation process must have as one of its objectives the restoration of popular support for the rule of law. To test this hypothesis, 
Figure 6 reports the simple relationship between victimization experiences and support for the rule of law among Cambodians older than 35 years old at the time of the interview.

\section{[PLACE FIGURE 6 ABOUT HERE]}

As the figure depicts (and the statistics confirm), practically no relationship exists between victimization experiences and support for the rule of law. Rule of law attitudes vary insignificantly across the various levels of victimization. As the figure clearly shows, support for the rule of law has very little to do with being a victim of KR atrocities.

We believe this is an important empirical finding that runs counter to much conventional wisdom. Individual citizens need not directly experience violations of the rule of law; instead, observing the victimization of others has similar consequences for how one evaluates law. As with political effects of the economy (e.g., Mutz and Mondak 1997), it is not one’s own experiences (egocentric) that determine attitudes but rather one's perceptions of the experiences of the society (sociotropic). Especially given the breadth of the KR's oppression of Cambodians, it seems to matter little whether an individual was victimized or not. The KR victimized the entire society.

\section{Discussion and Concluding Comments}

From the analysis presented in this paper, we draw several conclusions. First, on the eve of the KR trials, support for the rule of law is remarkably widespread in Cambodia. Second, we find no evidence whatsoever that disrespect for the rule of law is a legacy of the impunity the KR leaders enjoyed for decades. Instead, it seems that the failure to bring the miscreants to account for their deeds has made ordinary Cambodians value the rule of law more, not less. Finally, the results showing no difference in respect for the rule of law between those who were old enough to have lived through the KR era and those who were not indicate that it is not necessary for individuals to have experienced directly the repression of the KR. The KR affected the entire society, victims and bystanders alike, and the effect of its activities has been to elevate the rule of law in the hearts and minds of the Cambodian people. 
We close this paper with a reiteration of our general argument about the effects of truth processes on a society. First, we assert that effects must be measured, not assumed. Second, measuring the consequences of truth processes is best accomplished through dynamic research designs in which change is actually assessed. Truth processes seek to change individuals and the societies in which they live. Static analysis is hard-pressed to draw firm conclusions about change.

Most important, it is crucial to understand the state of society prior to the implementation of a truth process if one is going to draw conclusions about effects. Without understanding the high level of support for the rule of law prior to the start of the ECCC, one might erroneously conclude that the process has created an elevated reverence for law. In fact, it seems more likely to us that societal support for the rule of law has led to demands for accountability for the leaders of the KR, and that therefore Cambodia's political culture may be a cause of the tribunal rather than an effect (although effects other than attitudes toward the rule of law are of course possible). Assessing the hypothesis that truth leads to reconciliation is a tricky and complicated business. The best approach to testing that hypothesis is to measure the state of society prior to and after the implementation of a truth process. 


\section{References}

American Association for Public Opinion Research. 2000. Standard Definitions: Final Dispositions of Case Codes and Outcome Rates for Surveys. Ann Arbor, MI.

Almond, Gabriel A., and Sidney Verba. 1963. The Civic Culture. Princeton: Princeton University Press.

Davis, Darren W., and Brian D. Silver. 2004. “Civil Liberties vs. Security: Public Opinion in the Context of the Terrorist Attacks on America.” American Journal of Political Science 48 (\#1, January): 2846.

Diamond, Larry. 1999. Developing Democracy: Toward Consolidation. Baltimore: Johns Hopkins University Press.

Duch, Raymond M., and James L. Gibson. 1992. “'Putting Up With' Fascists in Western Europe: A Comparative, Cross-Level Analysis of Political Tolerance.” Western Political Quarterly 45 (\#1, March): 237-273.

Etzioni, Amitai. 2000. “Social Norms: Internationalization, Persuasion, and History.” Law and Society Review 34 (\#1): 157-178.

Extraordinary Chambers in the Courts of Cambodia, 2009. “Case Information Sheet, Kang Guek Eav.” http://www.eccc.gov.kh/english/cabinet/files/Case Info_DUCH_EN.pdf. [Accessed September 26, 2009].

Gibson, James L. 2007. “Changes in American Veneration for the Rule of Law.” DePaul Law Review 56 (\#2, Winter): 593-614.

Gibson, James L. 2004. “Truth, Reconciliation, and the Creation of a Human Rights Culture in South Africa.” Law and Society Review 38 (\#1, March): 5-40.

Gibson, James L. 2003. “Russian Attitudes towards the Rule of Law: An Analysis of Survey Data.” In Law and Informal Practices: The Post-Communist Experience, edited by Denis J. Galligan and Marina Kurkchiyan. Oxford: Oxford University Press. Pp. 77-91.

Gibson, James L. 1998. “A Sober Second Thought: An Experiment in Persuading Russians to Tolerate.” 
American Journal of Political Science 42 (\#3, July): 819-850.

Gibson James L. and Richard D. Bingham. 1985. Civil Liberties and Nazis: The Skokie Free Speech Controversy. New York: Praeger.

Gibson, James L., and Gregory A. Caldeira. 1996. “The Legal Cultures of Europe.” Law and Society Review 30 (\#1, April): 55-85.

Gibson, James L., and Amanda Gouws. 1997. "Support for the Rule of Law in the Emerging South African Democracy.” International Social Science Journal 152 (June): 173-191.

Hoffmann, Erik P. 1998. “Democratic Theories and Authority Patterns in Contemporary Russian Politics.” In Can Democracy Take Root in Post-Soviet Russia? Explorations in State-Society Relations, ed. By Harry Eckstein, Frederic J. Fleron Jr., Erik P. Hoffmann, and William M. Reisinger (with Richard Ahl, Russell Bova, and Philip G., Roeder). Lanham, MD: Rowman \& Littlefield Publishers, Inc. Pp. 105-150.

Krygier, Martin. 1990. "Marxism and the Rule of Law: Reflections After the Collapse of Communism." Law \& Social Inquiry 15 (Fall): 633-663.

Levin, Martin A. 1972. "Urban Politics and Judicial Behavior." Journal of Legal Studies 1:193-221. Levin, Martin A. 1977. Urban Politics and Criminal Courts. Chicago: University of Chicago Press. Lipset, Seymour Martin.1994. “The Social Requisites of Democracy Revisited.” (1993 Presidential Address). American Sociological Review 59 (\#1, February): 1-22.

Mutz, Diana C., and Jeffery J. Mondak. 1997. “Dimensions of Sociotropic Behavior: Group-Based Judgments of Fairness and Well-Being.” American Journal of Political Science 41 (January): 284-308.

Report of the Secretary-General. 2004. "The Rule of Law and Transitional Justice in Conflict and PostConflict Societies.” S/2004/616. United Nations. http://daccessdds.un.org/doc/UNDOC/GEN/N04/395/29/PDF/N0439529.pdf?OpenElement [accessed 3/20/2006]. 
Rose, Richard, William Mishler, and Christian Haerpfer. 1998. Democracy and Its Alternatives: Understanding Post-Communist Societies. Baltimore, MD: The Johns Hopkins University Press.

Solomon, Peter H., Jr. 1992. "Legality in Soviet Political Culture: A Perspective on Gorbachev's Reforms." In Stalinism: Its Nature and Aftermath: Essays in Honour of Moshe Lewin. Edited by Nick Lampert and Gabor T. Rittersporn. New York: M. E. Sharpe, Inc. Pp. 260 - 287.

Sonis, Jeffrey, James L. Gibson, Joop T. V. M. de Jong, Nigel P. Field, Sokhom Hean, and Ivan Komproe. 2009. “Probable Posttraumatic Stress Disorder and Disability in Cambodia: Associations with Perceived Justice, Desire for Revenge, and Attitudes Toward the Khmer Rouge Trials.” Journal of the American Medical Association 302 (\#5, August 5, 2009): 527-536.

Stouffer, Samuel C. 1955. Communism, Conformity and Civil Liberties. New York: Doubleday. Tamanaha. Brian Z. 2004. On the Rule of Law: History, Politics, Theory. New York: Cambridge University Press.

Transparency International. Corruption Perceptions Index, 2008. http://www.transparency.org/policy_research/surveys_indices/cpi/2008. [Accessed 9/20/09]. Wilson, James Q. 1976. Varieties of Political Behavior. New York: Basic Books. 
Figure 1. Support for the Rule of Law, Cambodia, 2007

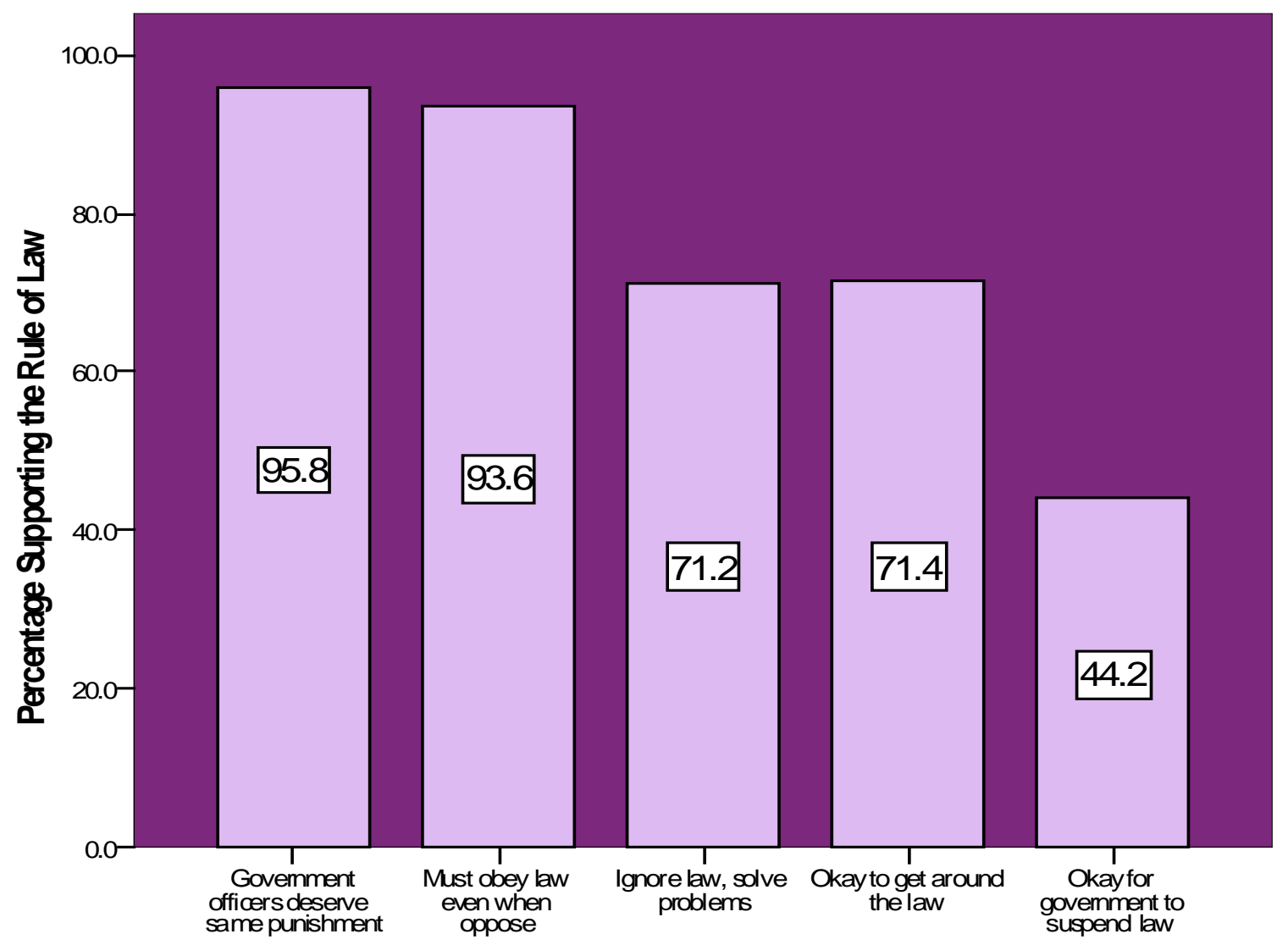

Note: The items (and the rule of law position) are:

Government officials who are guilty of crimes deserve the same punishment as anyone else. (Agree)

An individual is obligated to obey the law for the good of society as a whole, even if he/she finds it personally unjustifiable. (Agree)

Sometimes it might be better to ignore the law and solve problems immediately rather than wait for a legal solution. (Disagree)

It's alright to get around the law as long as you don't actually break it. (Disagree)

In times of emergency, the government ought to be able to suspend the law in order to solve pressing social problems. (Disagree) 
Figure 2. Cross-National Differences in Support for the Rule of Law, Necessary to Obey Even Unjust Laws

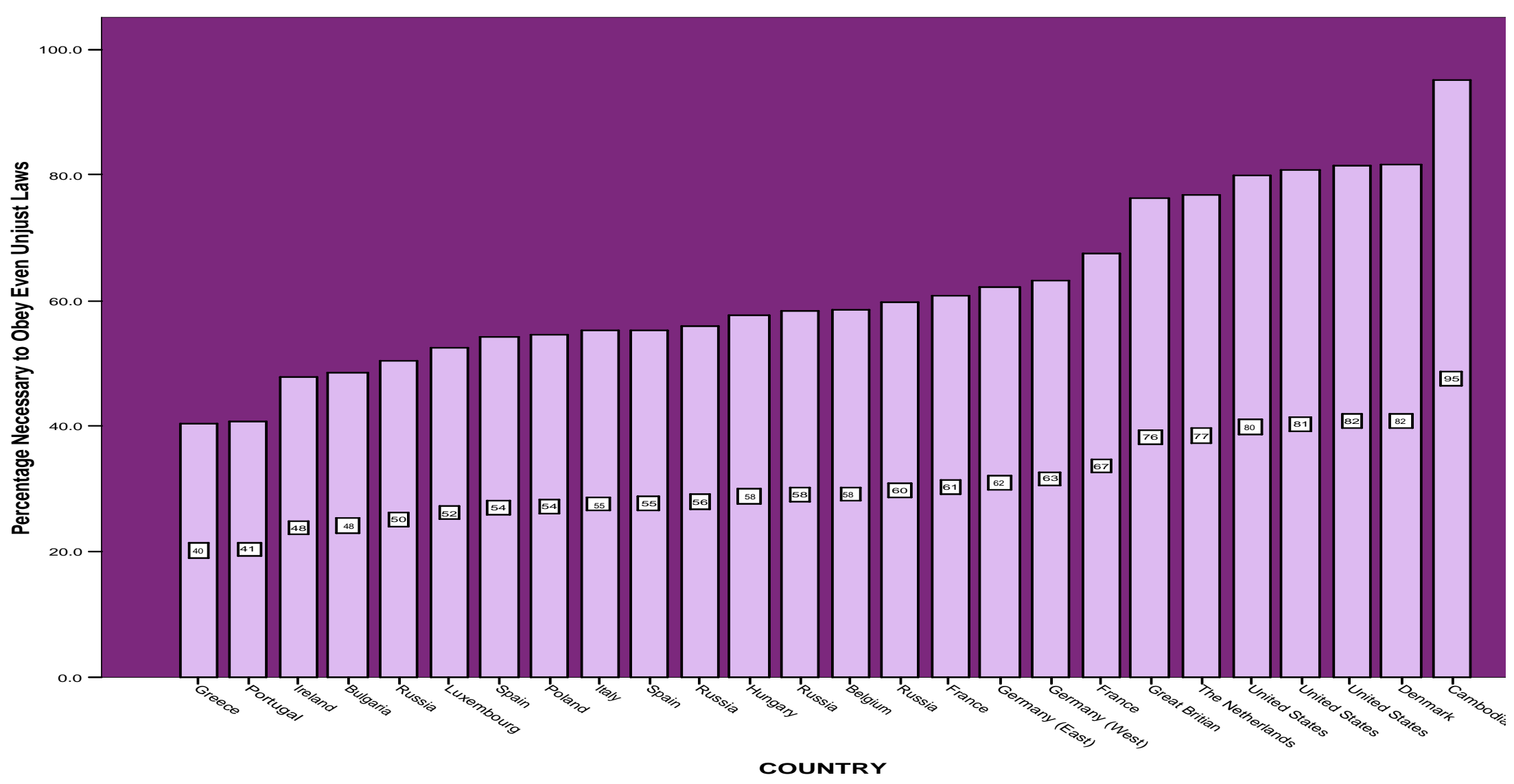


Figure 3. Cross-National Differences in Support for the Rule of Law, Against Ignoring Law in Order to Solve Problems

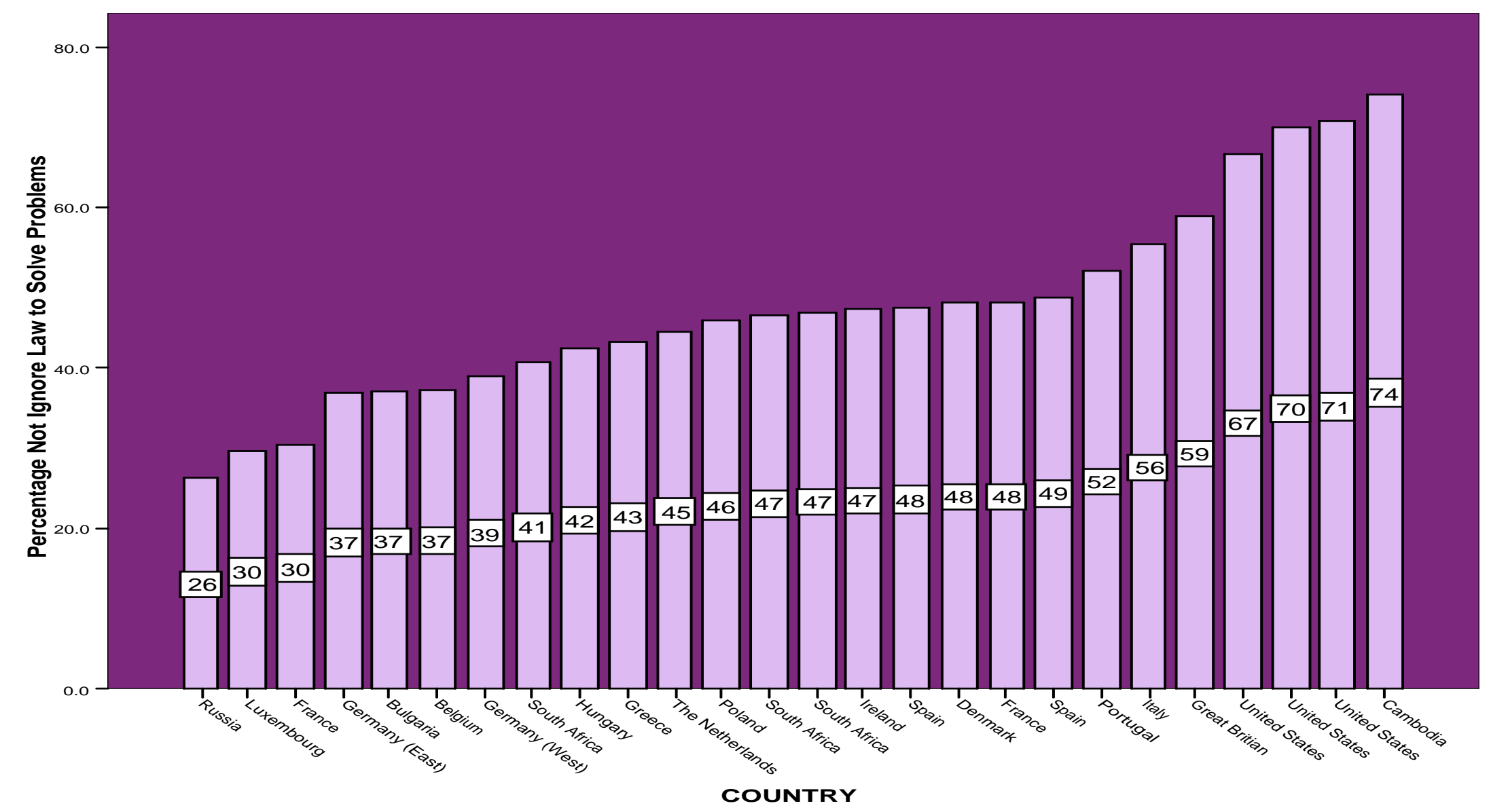


Figure 4. Respondent Age and Support for the Rule of Law

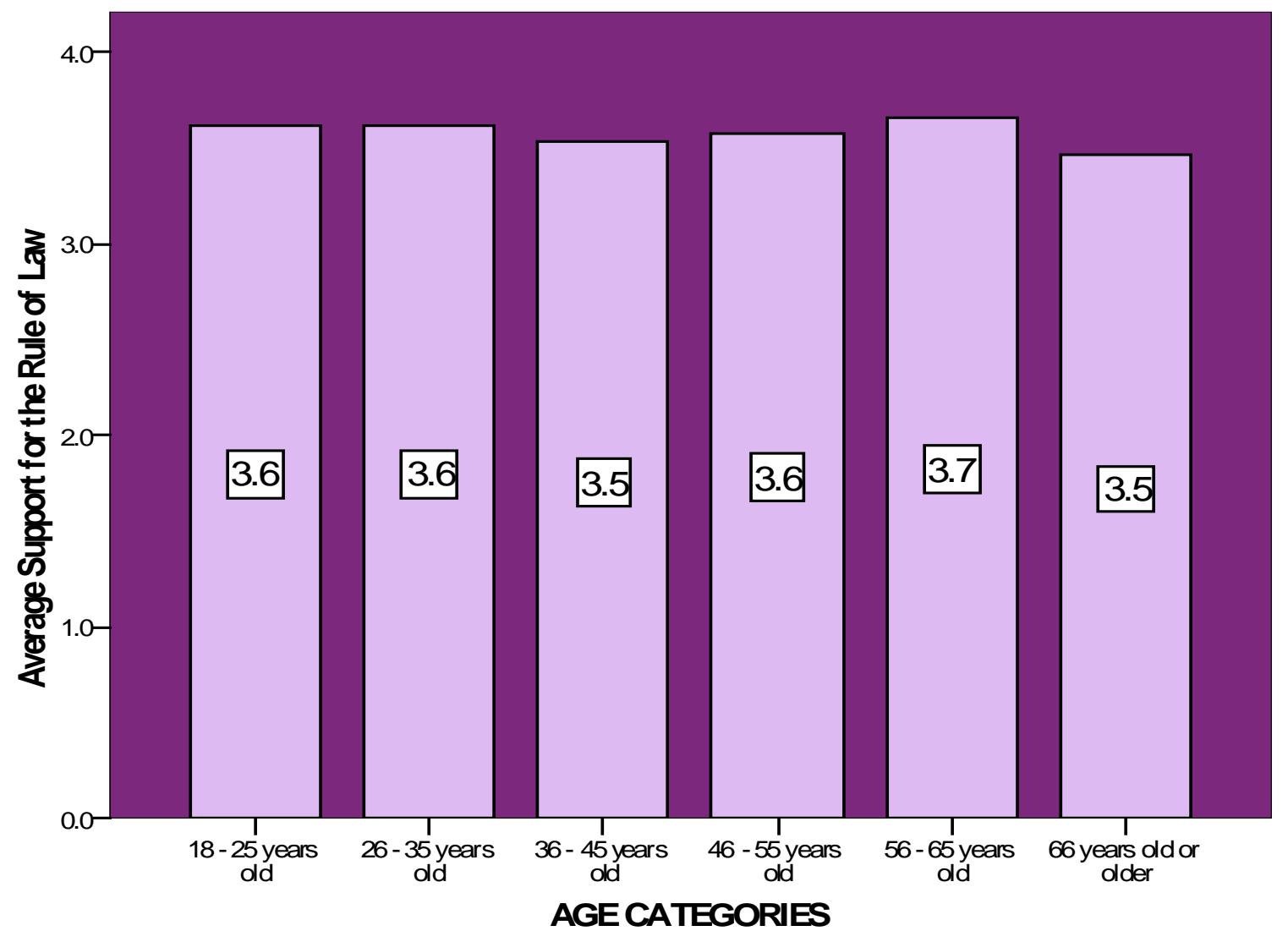


Figure 5. The Extent of Victimization under the Khmer Rouge

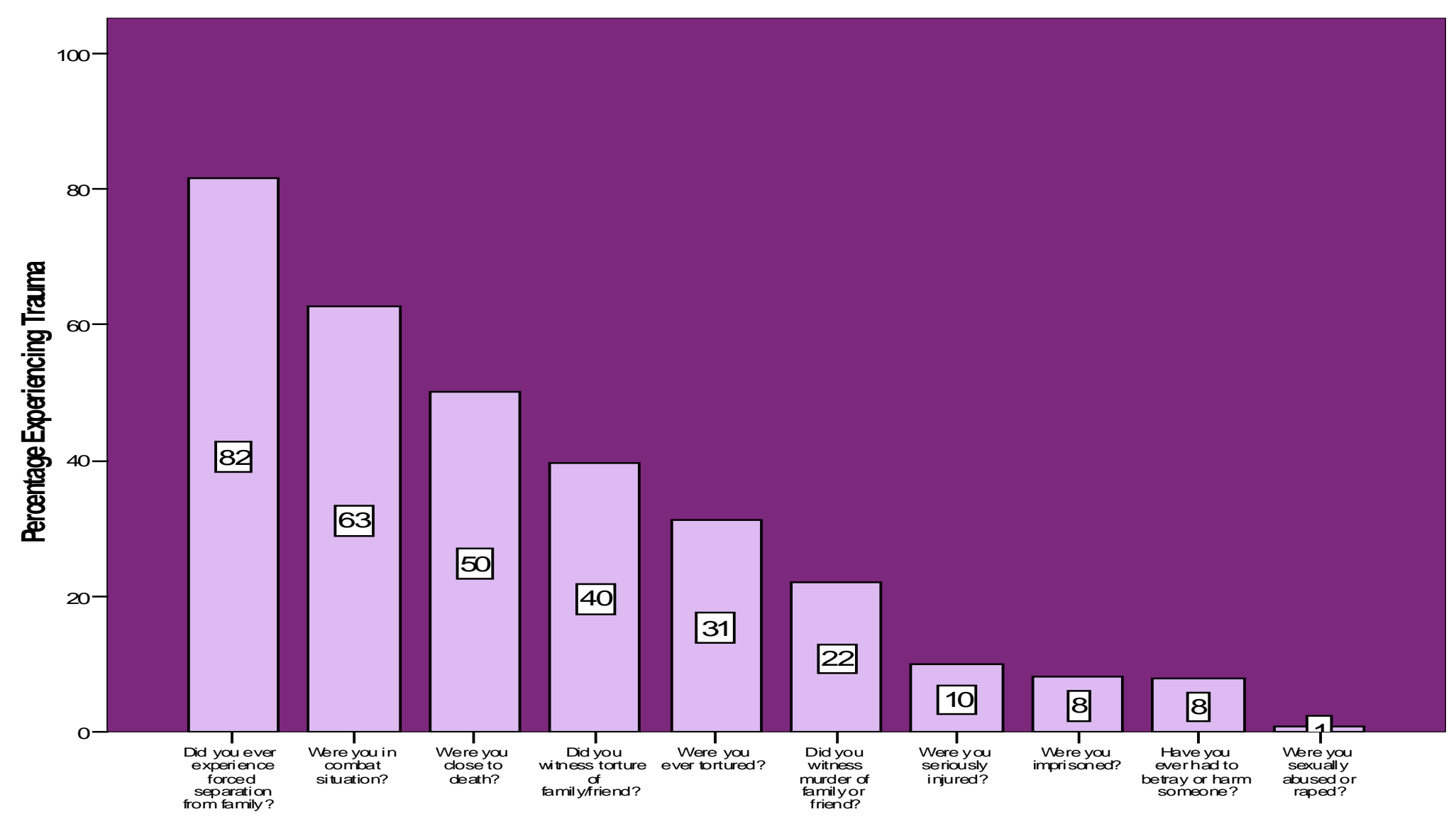


Figure 6. Victimization Experiences and Support for the Rule of Law

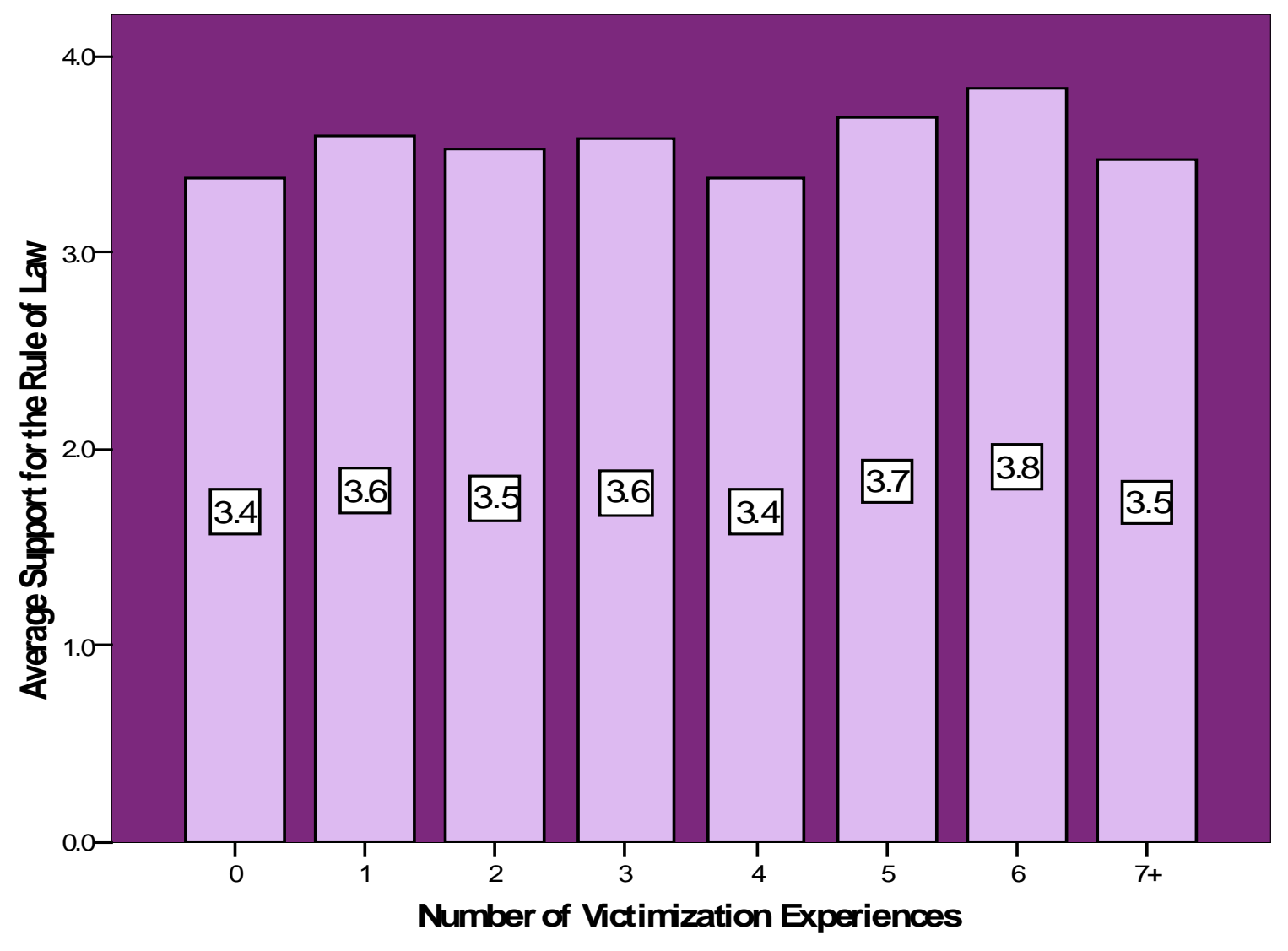

